\title{
Developing a blended learning based model for teaching foreign languages in engineering institutions
}

\author{
Alexandra V. Kudryashova ${ }^{1 \mathrm{a}}$, Tatyana N. Gorbatova ${ }^{1}$, and Nadezhda E. Rozhkova ${ }^{1}$ \\ ${ }^{1}$ Tomsk Polytechnic University, 634050 Lenin Avenue, 30, Tomsk, Russia
}

\begin{abstract}
The present paper deals with studying theoretical and methodical background of the concept of blended learning, which is the major didactic tool of the modern methods of foreign languages teaching. It also considers the principles of integrating blended learning in teaching foreign languages in engineering institutions. The basics of pedagogical modelling used for developing a model of integrating blended learning in the foreign language teaching are defined. The schematic model representation is given and the way of implementing the described model into the educational process is shown via the example of the lesson on "Cohesive devices".
\end{abstract}

\section{Introduction}

Nowadays the system of higher professional education in Russia is facing a great number of obstacles when turning to the new educational standards which control the professional level of specialists training in accordance with the unified educational standards. Global unification of educational systems is aimed at intensifying academic mobility, increasing integration of research study, extending academic networking, and eliminating language and cultural differences. This will definitely result in the increased level of internationalization.

However, the adoption of new standards of education revealed some problems largely caused by unpreparedness of educational system to change the conventional controlling mechanisms. Another major problem concerned the situation on the labour-market which turned out to be absolutely unprepared to deal with bachelor's degree specialists. Consequently, this has led to the situation that a university diploma is not a proof of professional qualification and a guarantee of employment any more.

At present Russian and European universities have no illusions about fast gap removal between «the position we occupy now» and «the position we want to occupy». This is a time- and labor- consuming process which needs a circumspect and strategic planning. Thereupon, we consider the primary task to be fulfilled in this situation is to reveal the existing problems, identify more thoroughly the outcomes and determine the list of initiatives which can help to smooth the gaps.

According to some researchers the main obstacles hampering the efficient and intensive development are the following:

1. poorly updated material and technical base;

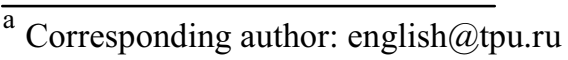

2. inertness of students and teachers to obtain and improve their knowledge independently;

3. reduction of classroom hours for disciplines acquiring;

4. a low level of academic mobility caused by insufficient language proficiency [1].

As a result of limiting classroom hours intended for mastering some disciplines there arises the necessity to find approaches enabling to optimize teaching and learning. Integration of blended learning method being a hybrid of face-to-face learning and distance learning can become a wise solution to the problem stated.

This didactic aspect is worth examining in details.

\section{Materials and methods}

According to Charles R. Graham (2013) blended learning is a complex of face-to-face learning, and technology-mediated learning [2]. We can assume that technology-mediated learning can be represented by elearning and distance learning. Thus, face-to-face learning means regular contact between a teacher and a student which provides an opportunity of discussing the material. E-learning provides students with multimedia or information technologies which make learning materials easily accessible at any time. Distance learning is effective in making up the curricula which can be used for the further education courses while obtaining a second university degree [3].

Implementation of blended learning-based techniques has some benefits both for teachers and students. These are the following advantages:

1. flexibility of the blended learning paradigm (this makes it possible to vary the proportion of learning components, to set the pace and time for 
teaching and learning);

2. improvement of teaching and learning quality (due to the usage of the more effective model as it combines the optimal aspects of the traditional and innovative teaching method);

3. an opportunity to modify learning activities (with the help of using electronic resources);

4. an increase of students' motivation to studying (by means of introducing more appealing forms of work);

5. time saving in class (by offering some learning material to be studied individually and some tasks to be accomplished remotely);

6. teacher's control and students' self-control (for example, by fixing deadlines for completing tasks);

7. opportunity for teachers to put and for the advanced students to master the higher complexity course materials and do the accompanied exercises (in order to perfect the advanced students' knowledge);

8. learners' continuous access to online educational resources (which allows students to constantly increase knowledge and revise the course material);

9. developing students' skills on planning and organizing their learning activity (basing on the goals set and the results anticipated);

10. feedback exchange (which is important both for a teacher and a student) [4].

Considering everything mentioned above, it is possible to conclude that the blended learning method combines the most efficient methods of teaching and is a harmonious combination of all components on condition that the teaching and learning are correctly organized. Efficient organization of the teaching and learning process can be achieved by careful course planning and choosing the optimal teaching and learning methods according to the requirements, goals and objectives of a definite course and a definite audience [5]. To accomplish these requirements, the method of process modeling is used. This method is effective to see the teaching and learning process as the system and to develop its internal and external correlations.

Modeling is the method of scientific research and knowledge. It implies designing and researching a prototype of an object to study it deeper. The prototype is called a model, which substitutes the original in some parameters. Modeling is widely used in pedagogy for optimizing the teaching and learning process planning, structuring the learning resources, diagnosing, directing the process of students' cognitive activity. Pedagogical modeling is a pedagogical design of learning events which implies the development of goals for creating pedagogical systems, processes or situations and the main ways of achieving them, as well as creation of a pedagogical model $[6,7]$.

At present, there exist 6 models relating to teaching and learning modeling in literature review.

«Face-to-Face Driver» model implies studying the largest part of a syllabus by means of classroom interaction between a teacher and students. The major part of the course is delivered into classroom environment; online resources are used partially to supplement the curriculum, and often involve only some students to participate. This is a traditional model.

"Flex» model implies most of the curriculum to be delivered in an electronic environment and the learning materials are offered in an online format. A teacher acts as a coordinator and provides the necessary guidance to practice the complicated material. This can be available in a group or individually.

«Rotation» model is based on students' moving between face-to-face interaction with a teacher in a classroom environment and online interaction via information communication technologies.

«Online Lab» model implies online courses offered on a specific site in equipped computer classes. In this model a lab assistant is responsible for supervising. In addition to online courses students have an opportunity to learn in a traditional class environment.

«Self-Blend» model provides students with an opportunity to take some additional courses further to the main ones. These courses can be provided by different education institutions. For successful implementation of this model students must be highly self-motivated.

«Online Driver» model of blended learning is ideal for students who need more flexibility and independence in their daily schedules. Students work mainly online but both face-to-face and online guidance are available [8].

There exist the so-called hybrids of blended learning models [9].

They are popular in Russia and imply:

1. combination and rotation of face-to-face and computer-mediated learning and interacting («Rotation» group, «Flipped classroom», )

2. Implementation of an individual approach («Personal preference» group, «New profile», «Individual curriculum», «Interacademic group» $[7,9]$.

The models of blended learning which belong to the «Rotation» group are characterized by fixed or flexible rotation of learning with a teacher and learning on-line. Each of three levels of the teaching and learning process (introduction of new material, exercising and drilling, skills revision) can be accomplished via classroom and virtual interaction. The proportion of personal and online interaction is determined by a teacher according to the teaching aims, the level of students' motivation, subject knowledge, and the level of informationcommunication competence. The teacher, applying the models of this group, has more freedom in organizing and running the course.

«Flipped classroom» model involves preliminary theoretical preparation to studies by means of providing the access to the on-line learning recourses. Classroom work implies practical activities focused on practicing the gained knowledge. The acceptable exercises to be included are the following: drilling exercises, participating into projects, presentations, speaking activities. The important condition for implementing this model is the Internet access. Launching the model is possible in the case when learners have approximately an equal level of language competence, motivation and 
psychological characteristics as the «Flipped classroom» model involves group work.

«Independent group» model is applied for effective learning within a group of students characterized by significant psychological peculiarities, different level of competence as the model implies working in different groups. One group predominantly works on-line and interacts with the teacher in a consulting way as another group has face-to-face classroom experience and uses electronic learning resources for practicing and drilling. The main factor for successful realization of the model is an opportunity to separate classroom space into two working areas. The teacher's role is complicated and implies an ability to allocate teacher's attention between two groups and to organize the learning process taking it into account.

"Work areas change» model is the most complicated in organizing and implementing as the number of groups increases in accordance with the types of learning activities: independent group work, individual work, online work. The efficiency of the model needs a large room to be zoned or some extra rooms to be accompanied by additional teaching assistance (tutors). The optimal number of rooms is four. The teacher has large-scale responsibilities as he/she has to organize a large number of groups.

The models belonging to «Personal preference» group execute a person-based approach in teaching and learning and are appropriate for upper-form pupils. The models are efficient for the students who are highly motivated and have a rather high level of information and communication competence as the process is largely based on using electronic educational resources, which implies the capacity for studying independently.

The only distinguishing feature of the aforementioned models is a method used to form groups. The «New profile» and the «Individual curriculum» models are implemented within students of the same grades but the «New profile» model involves a set of online courses while the «Individual curriculum» model comprises different sets of online courses, in comparison to them the «Interacademic group» model can combine different grades [9].

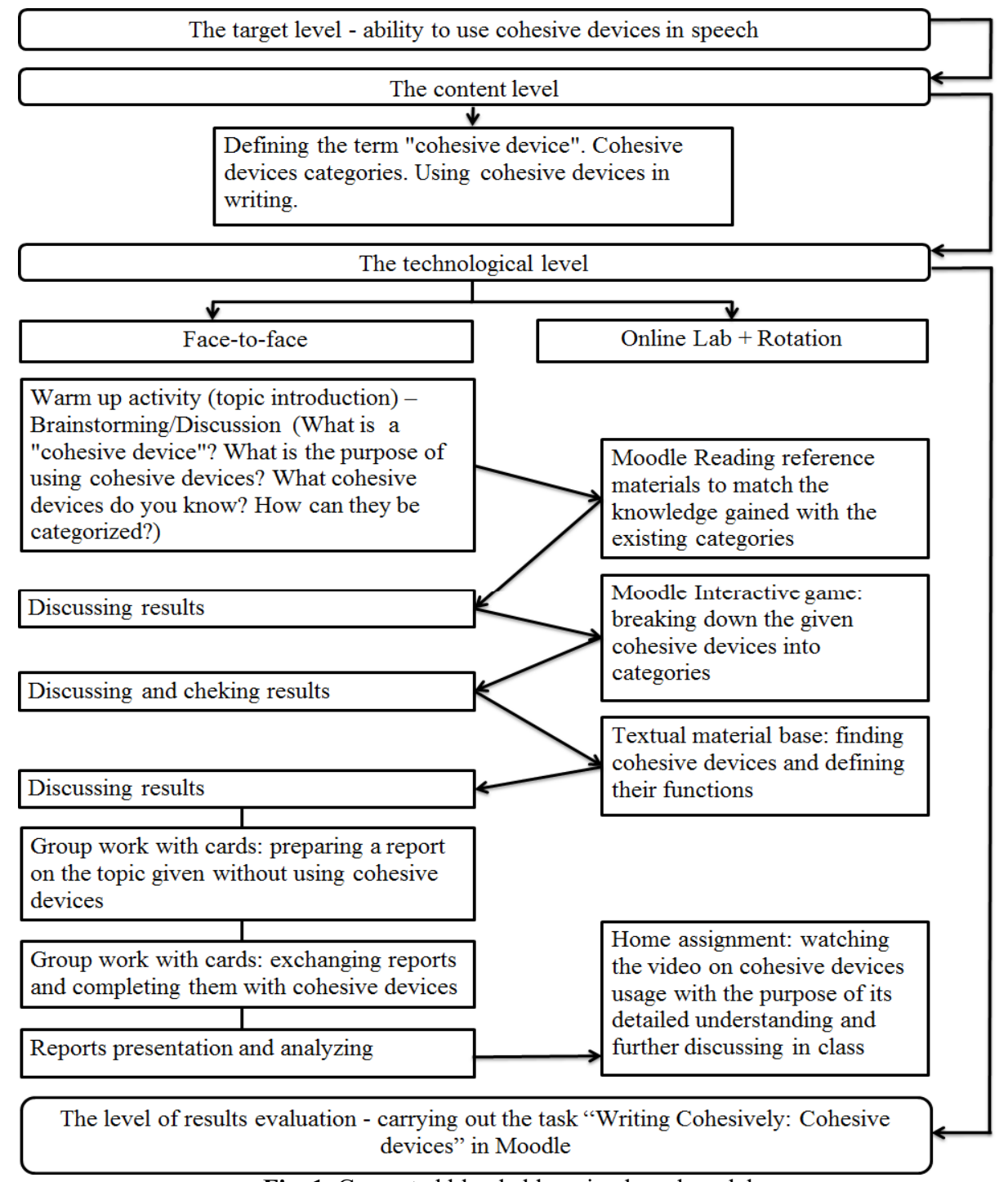

Fig. 1. Generated blended learning based model 
Each model of blended learning has its own distinguishing characteristics. Selection of a model for its further integration into the learning process is determined by the goals and objectives of the academic curriculum. Each of the models mentioned above comprises three main components of blended learning:

- direct interaction between the participants of learning process, which is considered to be traditional;

- online interaction between the participants of learning process based on electronic online resources and internet technologies;

- self-learning.

When choosing a model of blended learning it is necessary to take into account the level of students' motivation, their psychological characteristics, and the level of information and communication competence together with the level of the regulative learning activities.

Based on the goals and objectives as well as the specifics of learning English it can be assumed that the models belonging to the «Rotation» group can be considered as the most efficient to be integrated into the process of education. It is these models which make it possible to improve the process of learning the subject under the conditions of class time deficiency, different levels of students' training and motivation to study foreign language and foreign language for professional purposes.

Target, content, technological, organizational, evaluation and result levels are traditionally chosen when modeling a system $[10,11]$.

The target level defines the focus of the learning process and implies setting goals and objectives of the blended learning model. Its goals are to develop the foreign language competence for professional purposes, raise motivation, shape cognitive initiative and develop self-organization.

The content level denotes the information filling and includes knowledge and skills defining the focus of learning and teaching process as a whole.

The technological level involves development and implementation of the algorithm for creating the competences essential for engineers.

The level of results evaluation is intended to detect the professional competence maturity, to analyze the effectiveness of the pedagogies and tools applied as well as to perform corrective actions which intensify further development of professional competence [11].

\section{Results and discussion}

Let us present the implementation of blended-leaning model in the process of professional English teaching for the third year bachelor degree students. Let us image the stages as a graphic model (figure 1).

To introduce the model it is worth saying that each part of the material discussed in a class should be accompanied by a set of assignments online, and as a rule these are specialized LMS (Learning Management System) platforms. This is due to the fact that the major characteristic of blended learning is the concurrent electronic and traditional training. The tasks on video comprehension are recommended to be carried out as unsupervised activities while individual watching contributes to the deeper study of material and linguistic notions studying due to the repeated reference to the material. The level of results evaluation is presented in the generated model in the mode of carrying out tasks in Moodle, which can add to the material studied in class.

\section{Conclusion}

The effectiveness of integrating the blended learning model into the teaching and learning process is students' transition to the higher level of acquiring knowledge and developing skills, including the off-line learning ones, as the integration of blended learning model allows to:

1. provide an individual approach in teaching and learning;

2. save time in class;

3. create a generally acceptable electronic database of learning resources;

4. provide constant-time access to resources for students;

5. increase the quality of communication between a student and a teacher.

\section{References}

1. J. J. Forest, P. G. Altbach, International handbook of higher education (Dordrecht: Springer, 2006)

2. C. R. Graham, W. Woodfield, J. B. Harrison, The internet and higher education, 18, 4-14 (2013)

3. T. Filippova, Procedia-Social and Behavioral Sciences, 206, 348-353 (2015).

4. C. J.Bonk, Curtis, C. R. Graham, The handbook of blended learning: Global perspectives, local designs (John Wiley \& Sons, 2012)

5. T. Krasnova, Procedia-Social and Behavioral Sciences, 166, 399-403 (2015)

6. R. Koper, C. Tattersall, eds., Learning Design. A Handbook on Modelling and Delivering the Networked Education and Training (2005)

7. G. C. Conole, Review of Pedagogical Models and their use in e-learning (Milton Keynes: Open University, 2010)

8. E. Prokhorets, M. Plekhanova, N. Scherbinina, Procedia - Social and Behavioral Sciences, 215, 161-169 (2015)

9. C. M. Christensen, M. B. Horn, H. Staker. Is K-12 blended learning disruptive: An introduction of the theory of hybrids. The Christensen Institute. http://www. Christensen institute. org/wpcontent/uploads/2013/05/Is-K-12-Blended-

Learning-Disruptive. pdf. (2013)

10. R. Koper, Modeling units of study from a pedagogical perspective: the pedagogical metamodel behind EML (2001)

11. F. Dubin, E. Olshtain, Course design (Shanghai Foreign Language Education Press, 2002) 